\title{
Africanidades presentes em patrimônios da cultura material e imaterial em Alcântara/MA
}

\author{
Africanities present in material and immaterial culture heritage in Alcântara/MA
}

\author{
Ricardo Costa de Sousa* \\ Marisvaldo Silva Lima**
}

Palavras-chave:

Patrimônio Cultural

Africanidades

Alcântara/MA

Keywords:

Cultural Heritage

Africanities

Alcântara/MA
Resumo: Este escrito tem como objetivo central discutir as africanidades presentes em patrimônios da cultura material e imaterial no município histórico de Alcântara, no Estado do Maranhão, atentando-se às contribuições dos remanescentes de escravos na sua construção e manutenção, de modo a potencializar elementos fundantes da cultura africana no patrimônio da cidade. Assim, este escrito problematiza a diversidade patrimonial e colabora, de forma significativa, para a formação identitária dos alcantarenses. Para esta escrita, procuraram-se as contribuições em documentos produzidos pelo Instituto do Patrimônio Histórico e Artístico Nacional (IPHAN), bem como referências que tratem as africanidades presentes em patrimônios da cultura material e imaterial. Consequentemente, utilizaram-se pesquisas de campo, nas quais se registrou o ouvido, o vivido e o sentido, de modo a reunir subsídios que apontem a relação dos descendentes de escravos em Alcântara com o patrimônio material e imaterial da cidade. Pode-se concluir, a partir da pesquisa documental, bibliográfica e de campo, que há uma nítida relação e correlação entre o patrimônio da cultura material e imaterial, em que se circunscrevem os descendentes de escravos, pois se compreende que as ruínas de casarões antigos abundantes em Alcântara são espaços não somente de preservação e manutenção, de encontros de festejos, de lazer e expressões religiosas - em que se misturam o sagrado e o profano - como também onde identidades se constroem e reconstroem no fortalecimento de memórias do passado e do presente.

Abstract: This writing aims to discuss the africanities present in material and immaterial culture patrimony in the historic town of Alcântara, State of Maranhão, paying attention to the contributions of slave remnants in their construction and maintenance, in order to enhance founding elements of the African culture in the city patrimony. Thus, this writing problematizes patrimonial diversity and contributes, significantly, to the identity formation of the alcantarenses. For this writing, were sought the contributions in documents produced by the Instituto do Patrimônio Histórico e Artístico Nacional (IPHAN), as well as references that deal with the africanities present in material and immaterial culture heritage. Consequently, field researches was used, in which the listened, the experienced and the felt were recorded, in order to gather subsidies that point out the relationship of the descendants of slaves in Alcântara with the material and immaterial patrimony of the city. It can be concluded from the documentary, bibliographical and field research that there is a clear relationship and correlation between the material and immaterial culture patrimony, in which the descendants of slaves are limited, because it is understood that the abundant ruins of mansions ancient in Alcântara are also spaces for preservation and maintenance, for meetings of celebrations, leisure and religious expressions - in which the sacred and the profane blend - as well as spaces where identities are built and reconstructed in the strengthening of memories of the past and of the present.

\footnotetext{
* Doutor em Educação pelo Programa de Pós-Graduação em Educação da Universidade Federal do Rio Grande do Sul (UFRGS) e Militante do Centro de Cultura Negra Negro Cosme (CCNNC) de Imperatriz/MA. E-mail: ricardo_lut@hotmail.com

${ }^{* *}$ Acadêmico do mestrado em Jornalismo do Programa de Pós-graduação em Jornalismo da Universidade Federal de Santa Catarina (UFSC). Militante do Centro de Cultura Negra Negro Cosme (CCNNC) de Imperatriz/MA. E-mail: <mlimajornalista@gmail.com>
} 


\section{Introdução}

O município de Alcântara, Maranhão, é conhecido por ser o local onde o governo brasileiro construiu, na década de 1980, a base de lançamento de foguetes denominada Centro de Lançamento de Alcântara e por ser palco de diversos conflitos territoriais decorrentes dessa medida. Entretanto, a importância dessa cidade vai além de seu potencial para o lançamento de projéteis aeroespaciais. Alcântara é uma cidade histórica reconhecida mundialmente por seu conjunto arquitetônico, tombado pelo Instituto do Patrimônio Histórico e Artístico Nacional (IPHAN), e por suas manifestações culturais peculiares.

A formação populacional de Alcântara é majoritariamente negra. Outrora, foi um reduto escravista, hoje, em seu território, estão presentes mais de 150 comunidades remanescentes de quilombolas reconhecidas pela Fundação Palmares, as quais resistem às mudanças culturais e sociais que interferem em seus modos de vida, calcados na tradição e raiz afrodescendente.

Nesse sentido, o objetivo central deste trabalho é discutir as africanidades presentes nos patrimônios culturais materiais e imateriais no município de Alcântara, atentando-se para as contribuições dos remanescentes de escravos na construção e manutenção da cultura africana no patrimônio da cidade.

Procuraram-se as contribuições em documentos produzidos pelo Instituto do Patrimônio Histórico e Artístico Nacional (IPHAN), bem como em autores que permitem pensar sobre os patrimônios da cultura material e imaterial em territórios negros, a exemplo de Barros e Ramassote (2009a); Oliveira (2008); Possamai (2012); Carvalho (2008); Souza Filho e Andrade (2012), dentre outros. Realizou-se, também, pesquisa de campo, de modo a reunir subsídios que apontem essa relação.

\section{Alcântara: de celeiro econômico do Maranhão colonial a patrimônio cultural}

$\mathrm{Na}$ cidade de Alcântara, a diversidade patrimonial é impressionante e não só contribui de forma significativa para a formação identitária dos alcantarenses como também permite reconhecer seu passado e compreender o presente, de modo a poder modificá-lo (SOUZA FILHO; ANDRADE 2012). Outrora, foi Alcântara espaço de desenvolvimento expressivo, alcançando status de "Celeiro do Maranhão", devido à mão de obra escrava em produções ligadas ao cultivo de arroz, cana-deaçúcar e algodão, no século XVIII. Contudo, ao longo século XIX, em virtude da evolução das técnicas agrícolas, da exploração excessiva do solo, do fim da Companhia Geral de Comércio, da Independência do Brasil e, principalmente, da abolição da escravatura, Alcântara entrou em uma profunda estagnação (SOUSA, 2014). Entretanto, segundo o IPHAN (2015), seu conjunto se manteve preservado justamente devido ao isolamento da cidade, ocorrido a partir da segunda metade do século XIX em razão da decadência do comércio e dos produtos agrícolas que, até então, eram a fonte da riqueza local.

O tombamento justificou-se pela existência de um importante conjunto da arquitetura colonial luso-brasileira, consolidado durante todo o século XVII. Durante esse período, a cidade concentrou, de meados do século XVII até quase o final do século XIX, uma aristocracia rural agroexportadora de algodão e viveu um longo período de grande ascensão com a prosperidade econômica de todo o estado do Maranhão (IPHAN, 2015). Quem vai a Alcântara percebe, ao adentrar em meio aos grandes casarões históricos, a magnitude de sua riqueza construída em outros tempos.

Compõem o patrimônio de Alcântara diversas igrejas antigas, um forte do século XVIII e palacetes em ruínas, que demonstram a acentuada influência europeia sofrida pelo contato dos filhos das famílias ricas com a cidade de Coimbra (Portugal) durante seu período áureo. As ruínas, dispostas por boa parte da área urbana de Alcântara, são espaços de preservação e manutenção de encontros, festejos, lazer e expressão religiosa em que se misturam o sagrado e o profano, sendo também espaço onde identidades se constroem no fortalecimento de memórias do passado e do presente (SOUZA FILHO; ANDRADE 2012). As 
ruínas existentes nessa cidade carregam as marcas de profunda prosperidade e, ao mesmo tempo, de esquecimento.

Com o início do período de decadência econômica de Alcântara e o deslocamento das famílias para outras localidades, sobretudo a capital do estado (São Luís), houve um processo de subversão e ressignificação dos espaços físicos historicamente pertencentes aos senhores por parte dos ex-escravos e seus descendentes residentes naquele local, conforme Souza Filho e Andrade (2012, p. 89), dando aos casarões seculares “[...] outro sentido: o da valorização do sistema de crenças do grupo, de seu universo simbólico como patrimônio imaterial e, sobretudo, do significado dessas ruínas como marcador de sua identidade".

\section{A formação de africanidades no continente africano e no Brasil}

A diversidade patrimonial colabora de forma significativa para a formação e construção identitária da população alcantarense. Um conceitochave que cabe ser apresentado é o de africanidade. Munanga (1999), um dos grandes estudiosos da realidade negra no Brasil, destaca que foi a partir de meados do século XX que surgiu um movimento de autores que discutiram a unidade entre negros em todo o mundo independentemente de valores, ideias, crenças e religiosidades, vivenciados no continente africano, mas identificando pontos de unidade, para além da Negritude. Africanidade seria, então, um conjunto bastante amplo e diverso de elementos que, juntos, compõem certa coesão identitária entre os povos afrodescendentes, na África e nos países da diáspora.

Essa identidade, que é sempre um processo e nunca um produto acabado, não será construída no vazio, pois seus constitutivos são escolhidos entre os elementos comuns aos membros do grupo: língua, história, território, cultura, religião, situação social etc. Esses elementos não precisam estar concomitantemente reunidos para deflagrar o processo, pois as culturas em diáspora têm de contar apenas com aqueles que resistiram, ou que elas conquistaram em seus novos territórios. (MUNANGA, 1999, p. 14).

O excerto põe em evidência o processo de formação identitária. Esse processo é essencial para a tomada de consciência, pois é a partir dela que os sujeitos podem agir e ressignificar o mundo. Conforme Munanga (1996, p. 225), essa tomada e consciência é problemática no caso do Brasil, pois essa construção de identidade perpassa a cor da pele e, mais especificamente a cultura, ou seja, pela "produção cultural do negro". Para o autor, essa tomada de consciência perpassa, ainda, a contribuição histórica do negro na sociedade brasileira e na construção da economia do país, bem como a recuperação de sua história africana. Ao situar esses espaços, o autor sugere pensar que, para um indivíduo se sentir "negro", não precisa necessariamente frequentar um candomblé, assim como escutar samba ou outros tipos de músicas vinculadas a personalidades negras. De acordo com Munanga (1996, p. 225), a questão central reside no "processo de tomada de consciência" da sua contribuição nos diferentes campos da cultura.

De acordo com Arruda (2009), o conceito de africanidade perpassa os aspectos culturais e artísticos do povo africano; mas, não se limita a eles, pois abrange também aspectos históricos, políticos, linguísticos e outros comuns ao povo negro com notada influência no Brasil, devido ao contexto de escravidão ocorrido no país, que dá origem ao termo "africanidades brasileiras". Nessa direção, Silva (2005, p. 155) registra:

Ao dizer africanidades brasileiras estamos nos referindo às raízes da cultura brasileira que têm origem africana. Dizendo de outra forma, estamos, de um lado, nos referindo aos modos de ser, de viver, de organizar suas lutas, próprios dos negros brasileiros, e de outro lado, às marcas da cultura africana que, independentemente da origem étnica de cada brasileiro, fazem parte do seu dia-a-dia [sic].

$\mathrm{O}$ excerto indica que as africanidades brasileiras estão constantemente se formando, 
pois são resultado do engajamento da população afrodescendente na construção identitária nacional, "[...] deixando nos outros grupos étnicos com que convivem suas influências e, ao mesmo tempo, recebem e incorporam as destes" (SILVA, 2005, p. 156). Essas influências conferem, ainda, um determinado conjunto de características e valores, um ethos, ao mundo (PICOTTI, 2006).

Discutir a conceituação de africanidades contribui para compreender de que maneira elas se manifestam no patrimônio histórico cultural da cidade histórica de Alcântara. A pesquisa arqueológica é importante para definir patrimônio no âmbito do trabalho desenvolvido pelo IPHAN, como destacam Medeiros e Surya (2012, p. 294); esse tipo de pesquisa "[...] tem importância fundamental no processo de proteção do patrimônio, não apenas aquele com possibilidade de intervenção restaurativa, mas também o patrimônio na categoria de ruína, que já não apresenta condições de ser restaurado, mas possui uma riqueza vestigial". Nesse entendimento, reside a perspectiva etimológica e conceitual de patrimônio.

Conforme Possamai (2012, p. 111), “[...] a etimologia da palavra patrimônio liga-se à ideia de herança. Pressupõe cuidado com sua manutenção, guarda, aumento e aprimoramento com a finalidade de transmissão às futuras gerações". Dessa forma, a noção de patrimônio se confunde com a de propriedade herdada, como indica Oliveira (2008), quando registra que o processo pelo qual se forma um patrimônio é o de colecionar objetos, mantendo-os fora do circuito das atividades econômicas, sujeitos a uma proteção especial e expostos aos olhares dos homens. Nesse sentido, entende-se que o patrimônio está ligado à escolha, à seleção, realizada historicamente por um olhar especializado, daquele que se julga ser um objeto que merece ser protegido.

Portanto, o patrimônio é um acervo que registra os acontecimentos da história de um lugar, de uma sociedade, que pode se perder por falta de incentivo ou pela perda da identidade da comunidade com as mudanças e interferências do mundo globalizado (MEDEIROS; SURYA, 2012). Nessa direção, Possamai (2012, p. 14) argumenta que a política patrimonial dos acervos, historicamente, "[...] considerou o viés pedagógico dos bens culturais a serem preservados com o objetivo de representar a nação e ensinar sobre o passado às futuras gerações".

Segundo Possamai (2012), é importante compreender que o patrimônio é um conjunto de práticas e representações que se altera ao longo do tempo, ganhando contornos diferenciados de um período para outro. Nesse contexto, cabe ressaltar que "[...] quando a população se apropria e se reconhece nos bens culturais eleitos como representativos da nação, torna-se mais fácil atuar com políticas de preservação" (MEDEIROS; SURYA, 2012, p. 300). Desse modo, compreendese o patrimônio como uma reflexão potente para se pensar a população alcantarense enquanto um conjunto de sujeitos produtores de cultura material e imaterial. Assim, valorizar os bens culturais da população do referido município significa contribuir de forma significativa para a preservação da cultura herdada de gerações passadas.

É nessa relação de apropriação dos bens culturais das gerações passadas que é possível, segundo Machado (2004, p. 28), “[...] reativar os processos da memória, descobrindo como nossos antepassados produziam a satisfação de suas necessidades, como resolviam seus problemas imediatos e como se organizavam socialmente". Logo, é importante que a sociedade esteja envolvida com os patrimônios que a cercam, principalmente as construções mais antigas, porque elas remetem à história de uma época, o que possibilita estabelecer relações de pertencimento, e à valorização de uma identidade local, regional ou nacional. Conforme Machado (2004, p. 28), “[...] a estruturação dos sentimentos de identidade e de cidadania passa pela apropriação do patrimônio cultural e funda-se na capacidade de os grupos e atores sociais se sentirem sujeitos do processo de seleção e preservação do seu legado cultural".

A respeito do patrimônio cultural, Barros e Ramassote (2009a) e Possamai (2012) indicam duas questões que merecem destaque. A primeira remete ao entendimento de que a forma como Inglaterra, Alemanha, Estados Unidos e, principalmente, 
França entendiam seu patrimônio cultural exerceu grande influência no Brasil; segundo os autores, antigamente, o valor de um objeto era determinado pelo seu tempo de existência: quanto mais velho, mais valioso. A segunda questão se refere ao momento em que o governo passou a tomar conta do patrimônio cultural do Brasil, 1937, quando bens passaram a ser protegidos a partir de uma importância histórica ou artística. O resultado foi o tombamento das edificações vinculadas aos primeiros séculos de colonização portuguesa; como exemplo, citam-se os casarões coloniais e as igrejas barrocas, considerados pelos modernistas a autêntica cultura brasileira.

\section{Patrimônio cultural material e imaterial: aproximações e distanciamentos}

Desde a sua criação, em 1937, o IPHAN vem desenvolvendo ações voltadas à identificação, documentação, restauração, conservação, preservação, fiscalização e difusão da política patrimonial, com base em legislações específicas que abrangem um conjunto de bens culturais classificados segundo sua natureza, especificada nos quatro Livros do Tombo: arqueológica, paisagística e etnográfica; histórica; belas artes; e das artes aplicadas. Depois dessa classificação, houve discussão e estudos com a finalidade de pensar o patrimônio em duas categorias, a saber: bem material e bem imaterial, cada um com sua forma de preservação.

Entender o que é um patrimônio material parece simples e de fato é. Entra nessa categoria tudo aquilo que tem materialidade, ou seja, tudo que pode ser tocado, por exemplo: edificações, igrejas, quadros, esculturas, mobiliários, livros etc. Constituem o patrimônio material: os bens imóveis - núcleos urbanos, sítios arqueológicos e paisagísticos e bens individuais - e os bens móveis - coleções arqueológicas, acervos museológicos, documentais, bibliográficos, arquivísticos, videográficos, fotográficos e cinematográficos (BARROS; RAMASSOTE, 2009a; IPHAN, 2015; OLIVEIRA, 2008).
Nesse sentido, o patrimônio material é formado por um conjunto de bens culturais tangíveis, compreendidos como bens concretos que são resultantes da relação do homem com o espaço do qual faz parte. O patrimônio material engloba maneiras de vestir, hábitos alimentares, instrumentos musicais, obras de arte, técnica construtivas, monumentos, máquinas, móveis e moedas, entre outros. São bens portadores de referência à identidade, à memória de determinadas sociedades (BARROS; RAMASSOTE, 2009c). Por conseguinte, a importância do patrimônio material não está apenas na sua existência como objeto concreto e palpável, já que envolve uma série de elementos que os constitui, a exemplo, os indícios do passado, hora presentificados na cultura material.

O patrimônio material foi, durante muito tempo, considerado em sua essência como genuinamente um patrimônio, enquanto o patrimônio imaterial não recebeu esse mesmo status. Somente com a Constituição Federal de 1988, em seu art. 216, é que se trouxe para o ordenamento jurídico brasileiro a vanguarda dos conceitos internacionais de patrimônio cultural que englobassem também os bens de natureza imaterial, estes tomados individualmente ou em conjunto, portadores de referência à identidade, à ação e à memória nas diferentes populações, indígenas, negras ou brancas que formam a sociedade brasileira (BRASIL, 1988).

Contudo, a Constituição Federal de 1988 apenas sinalizava para a valorização do patrimônio cultural imaterial brasileiro. Somente em agosto de 2000, com o Decreto no 3.551, foi instituído o Programa Nacional do Patrimônio Imaterial (PNPI) (BRASIL, 2000). E, apenas a partir desse marco, a política de patrimônio cultural brasileiro tomou força e conquistou um espaço de discussão mais intensa. Sobre essa questão, cabe descrever aqui os objetivos elencados no site do IPHAN (2015) a respeito desse programa:

a) Implementar política de inventário, registro e salvaguarda de bens culturais de natureza imaterial; b) Contribuir para a preservação da diversidade étnica e cultural do país e para a 
disseminação de informações sobre o patrimônio cultural brasileiro a todos os segmentos da sociedade; c) Captar recursos e promover a constituição de uma rede de parceiros com vistas à preservação, valorização e ampliação dos bens que compõem o patrimônio cultural brasileiro; d) Incentivar e apoiar iniciativas e práticas de preservação desenvolvidas pela sociedade.

Os termos "bem imaterial", "patrimônio imaterial" ou "patrimônio da cultural imaterial" parecem estranhos; contudo, são simples de entender. Nem sempre o valor de um bem está manifestado em algo material; um exemplo, é o tambor de crioula, tombado como patrimônio cultural imaterial no ano de 2007. O valor e a importância dessa expressão não estão no tambor ou nas indumentárias, mas na manifestação em si. Estão na dança, nos espaços de socialização, nos brincantes, na musicalidade, na importância histórica que essa manifestação tem para seus participantes. Então, como não existe um objeto a ser preservado, é considerado um bem imaterial (BARROS; RAMASSOTE, 2009b).

Machado (2004, p. 16) acrescenta que o patrimônio imaterial engloba canções, crenças, celebrações, lendas e saberes que passam de uma geração para outra; manifestações cênicas, lúdicas e plásticas; lugares e espaços de convívio; e dialetos. Dessa forma, ao se falar de patrimônio da cultural imaterial, se está falando de bens culturais "vivos", de processos cuja existência depende de pessoas, grupos ou comunidades que são seus portadores (OLIVEIRA, 2008). Nesse sentido, sua salvaguarda envolve mais do que a preservação de objetos, inclui o registro de seu saber presente na oralidade da comunidade ou de grupos. Segundo Possamai (2012, p. 113),

[...] as culturas orientais e africanas, calcadas na oralidade, impuseram recentemente a relativização, pela Unesco, da noção ocidental materializada de patrimônio. Daí surgiu a noção ambígua e precária de patrimônio imaterial, com a finalidade precípua de contemplar os modos de vida, os saberes e fazeres, não necessariamente materializados em objetos, mas representados nos tesouros humanos vivos.

Patrimônio imaterial, ou intangível, é aquele que acontece em um determinado momento, mas que, mesmo não se materializando, se perpetua, a exemplo: procissões religiosas, fabricação de doces, formas de plantio e tradições - por exemplo, a capoeira. Essas manifestações são transmitidas de geração em geração, sendo constantemente recriadas e transformadas pelos grupos e pela comunidade (BARROS; RAMASSOTE, 2009c). Desse modo, o patrimônio imaterial não é estático, mas dinâmico.

Aparentemente, há uma dicotômica entre o patrimônio de cultura material e o imaterial; contudo, ela não existe. Esses bens culturais, ou seja, aqueles que foram ou são valorados positivamente, continuam exigindo uma análise que contribua para o estudo do passado e do presente. Nesse sentido, os bens culturais devem receber um tratamento que dê conta de sua historicidade, assim como da atuação de pessoas, grupos e/ou comunidades. Segundo Oliveira (2008), é preciso reforçar que os bens patrimoniais se reconfiguram e têm "ressonância"; fazem mediação entre o passado e o presente, entre o imaterial e o material, entre alma e corpo; e são condições e efeito de determinada modalidade de autoconsciência.

\section{Africanidade e os bens patrimoniais em Alcântara}

Como já exposto, a política patrimonial em Alcântara teve início em 1948 com o tombamento do conjunto arquitetônico e urbanístico da cidade pelo IPHAN e a concessão do título de Cidade Monumento Nacional devido à sua grande concentração de casarões do período colonial e de arquitetura luso-brasileira de meados do século XVII ao final do século XIX. À época, não se delimitou a área reconhecida e somente com a Lei ${ }^{\circ}$ 244, de 10 de outubro de 1997, é que se estabeleceu uma regulamentação específica para a área. Já em 2004, o IPHAN passou a considerar o patrimônio 
de Alcântara como de valor cultural, histórico, artístico, paisagístico, urbano e arqueológico (IPHAN, 2014).

A pesquisa de campo complementada com consulta ao acervo bibliográfico do IPHAN identificou os seguintes bens culturais, materiais e imateriais, tombados em Alcântara, apresentados a seguir:

\section{Quadro 1: Patrimônios culturais tombados em Alcântara/MA}

\begin{tabular}{|l|l|}
\hline Bens materiais & Bens imateriais \\
\hline Conjunto arquitetônico e urbanístico composto por: Casa de Câmara e Cadeia; & \\
Forte de São Sebastião; Solar Cavalo de Troia; Terminal de Passageiros; Mercado & \\
de Peixes; Antigo Matadouro; Casa de Cultura; Museu Histórico; Pousada & \\
do Imperador; Sobrado Tito Soares; Pousada do Pelourinho; Porto do Jacaré; & \\
Memorial Ruínas Clóvis Bevilacqua; Passos (construídos no século XVI, na rua da & \\
Amargura, para a representação da Páscoa); Capela de Nossa Senhora do Desterro & Tambor de crioula; Roda de \\
(Igreja do Desterro, atual Igreja de São José); Igreja de Nossa Sra. do Rosário dos & Capoeira; Bumba meu boi. \\
Pretos; Ruínas das igrejas de São Francisco; Igreja e convento de Nossa Senhora & \\
do Carmo; Igreja Matriz de São Matias; Rua do Jacaré; Fonte de Pedra; Fonte do & \\
Miritiva (Fonte do Mirititina); Centros de Pesquisa e Documentação da Imagem & \\
e do Som, de Artesanato, de Pesquisa e Experimentação de História Natural, e & \\
Cultural Netto Guterres; entre outros. & \\
\hline
\end{tabular}

Fonte: Adaptado de Instituto do Patrimônio Histórico e Artístico Nacional (2019a).

A pesquisa realizada apontou a existência de bens culturais imateriais não patrimonializados, como os que estão listados no Quadro 2, que englobam festejos populares, expressões artísticas e ofícios artesanais:

\section{Quadro 2: Bens culturais não patrimonializados em Alcântara}

\begin{tabular}{|l|l|}
\hline Manifestação & Descrição \\
\hline Festa do Divino Espírito Santo & Festejo mais importante e antigo registrado no município. \\
\hline Festejo de São Benedito & $\begin{array}{l}\text { Festejo em honra ao padroeiro dos negros no qual são realizadas rodas } \\
\text { de tambor de crioula. }\end{array}$ \\
\hline Festa de Santa Tereza & Festejo religioso da comunidade de Itamatatiua. \\
\hline Dança do Coco & $\begin{array}{l}\text { Dança tradicional do período junino identificada em algumas } \\
\text { comunidades quilombolas. }\end{array}$ \\
\hline Dança do Baiadeiro & Dança tradicional do período junino. \\
\hline Dança Portuguesa & $\begin{array}{l}\text { Expressão organizada por jovens alcantarenses que tem como referência } \\
\text { o folclore português. }\end{array}$ \\
\hline Cerâmica & $\begin{array}{l}\text { Artesanato produzido na comunidade de Itamatatiua exclusivamente } \\
\text { por mulheres quilombolas. }\end{array}$ \\
\hline Tecelagem com fibra de buriti & Atividade artesanal da comunidade de Santa Maria. \\
\hline Caixeiras do Divino & $\begin{array}{l}\text { Ofício exercido por mulheres que guardam conhecimentos profundos } \\
\text { sobre rituais de abertura e encerramento da Festa do Divino Espírito } \\
\text { Santo. }\end{array}$ \\
\hline
\end{tabular}

Fonte: Adaptado de Instituto do Patrimônio Histórico e Artístico Nacional (2019a).

Os dados apresentados sinalizam dois aspectos da política patrimonial em Alcântara. $\mathrm{O}$ primeiro deles diz respeito à definição dos bens considerados patrimônio, legitimando, quase sempre, apenas as expressões de um grupo hegemônico. Destaca-se que, em decorrência 
dessa exclusão, apenas um pequeno número de registros de bens pertencentes ao universo cultural afrodescendente ${ }^{1}$ são patrimonializados. Impera ainda, nos dias de hoje, uma visão “[...] colonizadora, monocultural e eurocêntrica, negando as histórias, as culturas, as memórias e as identidades das populações negras e indígenas" (PASSOS; NASCIMENTO; NOGUEIRA, 2016).

O segundo aspecto diz respeito ao tema central deste artigo: discutir africanidades presentes em bens materiais e imateriais em Alcântara. A partir da pesquisa de campo que utilizou como metodologia a observação direta durante atividades de pesquisa e extensão realizadas pelo Projeto ALMA, da Universidade Federal do Maranhão (UFMA), durante visitas, realizadas bimestralmente, no período de 2010 a 2013, à sede de Alcântara e 15 comunidades quilombolas, é possível afirmar que ruínas de casarões antigos e aqueles ainda de pé são abundantes em Alcântara. E essas construções são também espaços de preservação e manutenção de encontros, de festejos, de lazer e de expressões religiosas, em que se misturam o sagrado e o profano.

A Festa do Divino, celebração de origem portuguesa que faz referência a uma corte imperial imaginária, recebeu ao longo dos anos a forte influência afrodescendente com a inserção de caixeiras que resguardam a tradição de "abrir os caminhos" com seus cânticos e toques de tambor feito de couro de animal. Conforme destacam Gomes, Gastal e Coriolano (2015), ao se referir à Festa do Divino Espírito Santo em Alcântara, essa tradição centenária é seguida à risca, o que a torna um patrimônio cultural. Contudo, os autores esclarecem a existência de uma relação intrínseca entre culto e festa. No que se refere ao sagrado, os autores indicam os valores que se constroem para além de uma lógica racional e explicável, mas que subsiste um compromisso religioso; e, partir desses componentes comparece a divindade em questão. No que se refere ao profano, tem-se a festa em si, um compromisso dos devotos com a preservação do legado, das experiências profanas e sagradas dos ancestrais africanos.

Outra celebração festiva importante, mas pouco conhecida, é o Festejo de São Benedito, realizado no largo da Igreja de Nossa Senhora do Rosário dos Pretos (patrimônio tombado), que faz reverência a São Benedito, padroeiro dos negros, cozinheiros e africanos. Nessa festividade, são realizadas rodas de tambor de crioula em que se apresentam grupos da sede e das comunidades quilombolas. Representações da mais tradicional e reconhecida manifestação cultural afrodescendente patrimonializada no Maranhão, com traços da religiosidade e da cultura afrodescendente que podem ser observadas também na dança do coco, no Bumba meu boi (manifestação tombada em 2012), na dança do boiadeiro e na dança portuguesa, contribuição de negros e negras.

As comunidades quilombolas são representadas e identificadas por seus festejos populares, a exemplo da Festa de Santa Tereza D’ávila, na comunidade de Itamatatiua, mas também por outras expressões identitárias e econômicas, como a produção de artesanato local, que muito revela sobre a relação dos moradores com a natureza em seu entorno, assim como sobre a organização social da comunidade.

Destaca-se, ainda, o artesanato produzido com barro em Itamatatiua, uma das mais antigas comunidades quilombolas de Alcântara, cujas peças principais são potes, bilhas, travessas, panelas, moringas, cuias e canecas. Há, também, atividade tecelã com fibra de buriti na comunidade quilombola Santa Maria, onde são confeccionadas sacolas, esteiras, redes, pastas, bolsas, tapetes e outros objetos. É importante ressaltar que ambas as atividades representam uma fonte de renda para essas comunidades; mas, além disso, são estratégias de construção de discursos e de práticas alicerçadas na produção e no consumo da cultura local.

\section{Considerações finais}

A pesquisa documental, bibliográfica e de campo permite olhar para a relação e correlação entre o patrimônio da cultura material e imaterial em que se inserem os descendentes de escravos, bem como as africanidades presentes nos patrimônios culturais materiais e imateriais de Alcântara.

Alcântara, localizada no estado do Maranhão, conhecida popularmente como "museu 
a céu aberto", em cada milímetro de suas ruas de pedra e de seus casarões, resguarda centenários traços da identidade negra, seja pelo derramamento de sangue durante as décadas de escravidão africana naquele solo, seja pela ressignificação que as comunidades remanescentes de escravos atribuíram, ao longo dos anos, à sua existência.

Dessa forma, reconhecer os patrimônios da cultura material e imaterial dessa cidade é compreender as complexas identidades que confrontam o passado e o presente cotidianamente. É, na verdade, valorizar a história de sua população, ou seja, discutir o legado dos povos africanos no Brasil.

Por fim, ao se discutir africanidades presentes em patrimônios da cultura material e imaterial no município de Alcântara, a intenção residiu em apontar esse município como um celeiro econômico do período colonial brasileiro e em discutir como esse apogeu econômico reverberou na construção do seu patrimônio cultural e, em seguida, do imaterial, que foram construídos e reelaborados pelos descendentes de escravos.

\section{Notas}

1 Ver lista de bens tombados e processos em andamento no ano de 2019, disponíveis em: http://portal.iphan.gov.br/ uploads/ckfinder/arquivos/BENS\%20TOMBADOS\%20 E\%20PROCESSOS\%20EM\%20ANDAMENTO\%20 2019\%20MAIO.pdf. (IPHAN, 2019b) e em http://portal. iphan.gov.br/pagina/detalhes/681/ (IPHAN, 2019c).

\section{Referências}

ARRUDA, Jorge Bezerra. Africanidade do povo brasileiro: somos iguais e diferentes. São Paulo: Diáspora, 2009.

BARROS, Flávia Luz Pessoa; RAMASSOTE, Rodrigo Martins. Patrimônio Contado: Cultura e Educação - Livro 1. São Luís: Superintendência Regional do Iphan no Maranhão, 2009a.

BARROS, Flávia Luz Pessoa; RAMASSOTE, Rodrigo Martins. Patrimônio Contado: Cultura e Educação - Livro 2. São Luís: Superintendência Regional do Iphan no Maranhão, 2009b.
BARROS, Flávia Luz Pessoa; RAMASSOTE, Rodrigo Martins. Patrimônio Contado: Cultura e Educação - Livro 3. São Luís: Superintendência Regional do Iphan no Maranhão, 2009c.

BRASIL. Constituição (1988). Constituição da República Federativa do Brasil. Brasília, DF: Senado Federal, 1988.

BRASIL. Decreto n' 3.551, de 04 de agosto de 2000. Institui o Registro de Bens Culturais de Natureza Imaterial que constituem patrimônio cultural brasileiro, cria o Programa Nacional do Patrimônio Imaterial e dá outras providências. Disponível em: http://www.planalto.gov.br/ccivil_03/decreto/ D3551.htm. Acesso em: 30 maio 2019.

GOMES, Cristiane Mesquita, GASTAL, Susana; CORIOLANO, Luzia Neide. Hospitalidade na Festa do Divino: Seu Festejar em Alcântara e São Luís do Maranhão. CENÁRIO, Brasília, v. 3, n. 5, 87-104, dez. 2015.

INSTITUTO DE PATRIMÔNIO HISTÓRICO E ARTÍSTICO NACIONAL (IPHAN). 2015. Disponível em:_http://portal.iphan.gov.br/. Acesso em: 30 maio 2019.

INSTITUTO DE PATRIMÔNIO HISTÓRICO E ARTÍSTICO NACIONAL (IPHAN). Monumentos e Espaços Públicos Tombados - Alcântara (MA). 2019a. Disponível em: http://portal.iphan.gov.br/ pagina/detalhes/1438. Acesso em: 30 maio 2019.

INSTITUTO DE PATRIMÔNIO HISTÓRICO E ARTÍSTICO NACIONAL (IPHAN). Bens Tombados. 2019b. Disponível em: http://portal. iphan.gov.br/uploads/ckfinder/arquivos/BENS\%20 TOMBADOS\%20E\%20PROCESSOS\%20EM\%20 ANDAMENTO\%202019\%20MAIO.pdf. Acesso em: 18 ago. 2019.

INSTITUTO DE PATRIMÔNIO HISTÓRICO E ARTÍsTICO NACIONAL (IPHAN). Projetos Realizados de Identificação de Bens Culturais Imateriais. 2019c. Disponível em: http://portal. iphan.gov.br/pagina/detalhes/681/. Acesso em: 18 ago. 2019. 
INSTITUTO DE PATRIMÔNIO HISTÓRICO E ARTÍSTICO NACIONAL (IPHAN). Lei no 244, de 10 de outubro de 1997. Brasília, 2014. Disponível em: http://portal.iphan.gov.br. Acesso em: 18 ago. 2019.

MACHADO, Maria Beatriz Pinheiro. Educação Patrimonial: orientação para professores do ensino fundamental e médio. Caxias do Sul: Maneco Livr. \& Ed., 2004.

MEDEIROS, Mércia Carréra de; SURYA, Leandro. A importância da educação patrimonial para a preservação do patrimônio. In: SIMPÓSIO NACIONAL DE HISTÓRIA, 25., 2009, Fortaleza. Anais [...]. Fortaleza: ANPUH, 2009. CD-ROM.

MUNANGA, Kabengele. Rediscutindo a mestiçagem no Brasil: identidade nacional versus identidade negra. 2. ed. Belo Horizonte: Editora Autêntica, 2006.

MUNANGA, Kabengele. Origem e histórico do quilombo na África. Revista USP, São Paulo, n. 28, p. 56-63, dez./fev. 1996.

OLIVEIRA, Lúcia Lippi. Cultura é patrimônio: um guia. Rio de Janeiro: Editora FGV, 2008.

PASSOS, Joana Célia dos; NASCIMENTO, Tânia Tomázia do; NOGUEIRA, João Carlos. O patrimônio cultural afro-brasileiro: São José, um estudo de caso. Estudos históricos, Rio de Janeiro, v. 29, n. 57, p. 195-215, jan./abr. 2016.
PICOTTI, Dina. Africanidade. Grupo de Estudos e Pesquisas sobre a Globalização. 2006. Disponível em: http://www.mondialisations.org/php/public/ index.php Acesso em: 30 maio 2019.

POSSAMAI, Zita Rosane. Patrimônio e história da educação: aproximações e possibilidades de pesquisa. História da Educação - RHE, v. 16, n. 36, p. 110-120, jan./abr. 2012.

SILVA, Petrolina Beatriz Gonçalves e. Educação Aprendizagem e Ensino das Africanidades Brasileiras. In: MUNANGA, Kabengele (Org.). Superando o Racismo na escola. Brasília: Ministério da Educação, 2005. p. 155-172.

SOUSA, Ricardo Costa de. História da educação da população negra no município de Alcântara. Orientador: Alceu Ravanello Ferraro. 2014. 152 f. Dissertação (Mestrado em Educação) - Programa de Pós-Graduação em Educação, Faculdade de Educação, Universidade Federal do Rio Grande do Sul, Porto Alegre, 2014.

SOUZA FILHO, Benedito; ANDRADE, Maristela de Paula. Patrimônio imaterial de quilombolas limites da metodologia de inventário de referências culturais. Horizontes Antropológicos, Porto Alegre, ano 18, n. 38, p. 75-99, jul./dez. 2012. 